\title{
The Role of Alloy Composition, Environment and Stresses for the Oxidation Resistance of Modern 9\% Cr Steels for Fossil Power Stations
}

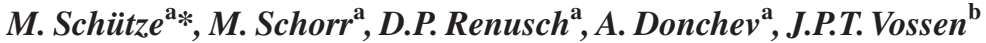 \\ ${ }^{a}$ Karl-Winnacker-Institut der DECHEMA e.V., Frankfurt/Main, Germany \\ ${ }^{\mathrm{b}}$ Volkswagen AG, Wolfsburg, Germany
}

Received: September 2, 2002; Revised: September 4, 2002

\begin{abstract}
In recent years a new group of ferritic-martensitic chromium steels for the use in fossil power stations has been developed with chromium contents between 9 and $12 \%$. Typical representatives of these steels are P91, E911 and Nf616, which are nowadays widely used in the more advanced power plants. In the development phase the focus was on the mechanical properties of these steels but when taking them to practical operation conditions it turned out that much of the life-time of the materials and components is determined by their oxidation properties. Oxidation resistance is first of all a function of alloy composition. For the steels of this group it is chromium, silicon, manganese and molybdenum that decide their oxidation performance and since the contents especially of the four elements can be significantly different for the different steels there can be clear differences in oxidation behaviour. One of the most important issues from this point of view is how the concentrations of these elements change in the metal subsurface zone during operation/oxidation since if their level drops below a critical level oxidation resistance of the steels will be lost. In the work to be reported the influence of alloy composition and metal subsurface zone concentration as a function of oxidation time up to $10000 \mathrm{~h}$ was investigated in dry air and air up to $10 \%$ water vapour at $650{ }^{\circ} \mathrm{C}$. The investigations comprised several of the advanced commercial 9\% Cr steels including P91, E911, Nf616 and six laboratory melts of Nf616 with different amounts of silicon. As the results of the investigations show humidity, which is omnipresent in combustion environments, can dramatically accelerate oxidation. Silicon as an alloying element reduces the detrimental effect of water vapour significantly while molybdenum has a negative effect. The effects of the key alloying elements in these steels was quantified for conditions with and without water vapour in the environment including the role of mechanical load and recommendations were developed on how to guarantee the optimum oxidation resistance of these steels.
\end{abstract}

Keywords: Cr steels, fossil power stations, oxidation

\section{Introduction}

In recent years an extensive materials development has taken place with regard to new steels for fossil power stations which is characterised in Fig. 1 for the $9-12 \% \mathrm{Cr}$ ferritic-martensitic steels ${ }^{1}$. This development work was mainly focused on the mechanical high temperature strength up to $650{ }^{\circ} \mathrm{C}$ and rather neglected the oxidation resistance of this group of steels. As shown in ref. 2 by experimental investigations and theoretical model calculations a change in oxidation resistance between protective and non-protective behaviour occurs at a chromium content of about $7 \%$ for the ferritic-martensitic steels. In other words the "dis-

*e-mail: schuetze@dechema.de

Presented at the International Symposium on High Temperature Corrosion in Energy Related Systems, Angra dos Reis - RJ, September 2002. tance" of 9-12\% Cr to the critical amount of $7 \% \mathrm{Cr}$ is not large and already a slight $\mathrm{Cr}$ depletion in the metal subsurface zone will endanger oxidation resistance if the originally protective oxide scale forms cracks and locally metal of less than $7 \% \mathrm{Cr}$ is exposed to the environment due to $\mathrm{Cr}$ depletion. This situation is illustrated by Fig. 2 where at the beginning (i.e. after $100 \mathrm{~h}$ ) a thin protective oxide scale is present while after $300 \mathrm{~h}$ first cracks in the oxide scale together with a $\mathrm{Cr}$ depleted metal subsurface zone lead to the local formation of fast growing iron rich oxide nodules. As will be shown later this effect is amplified by the pres- 


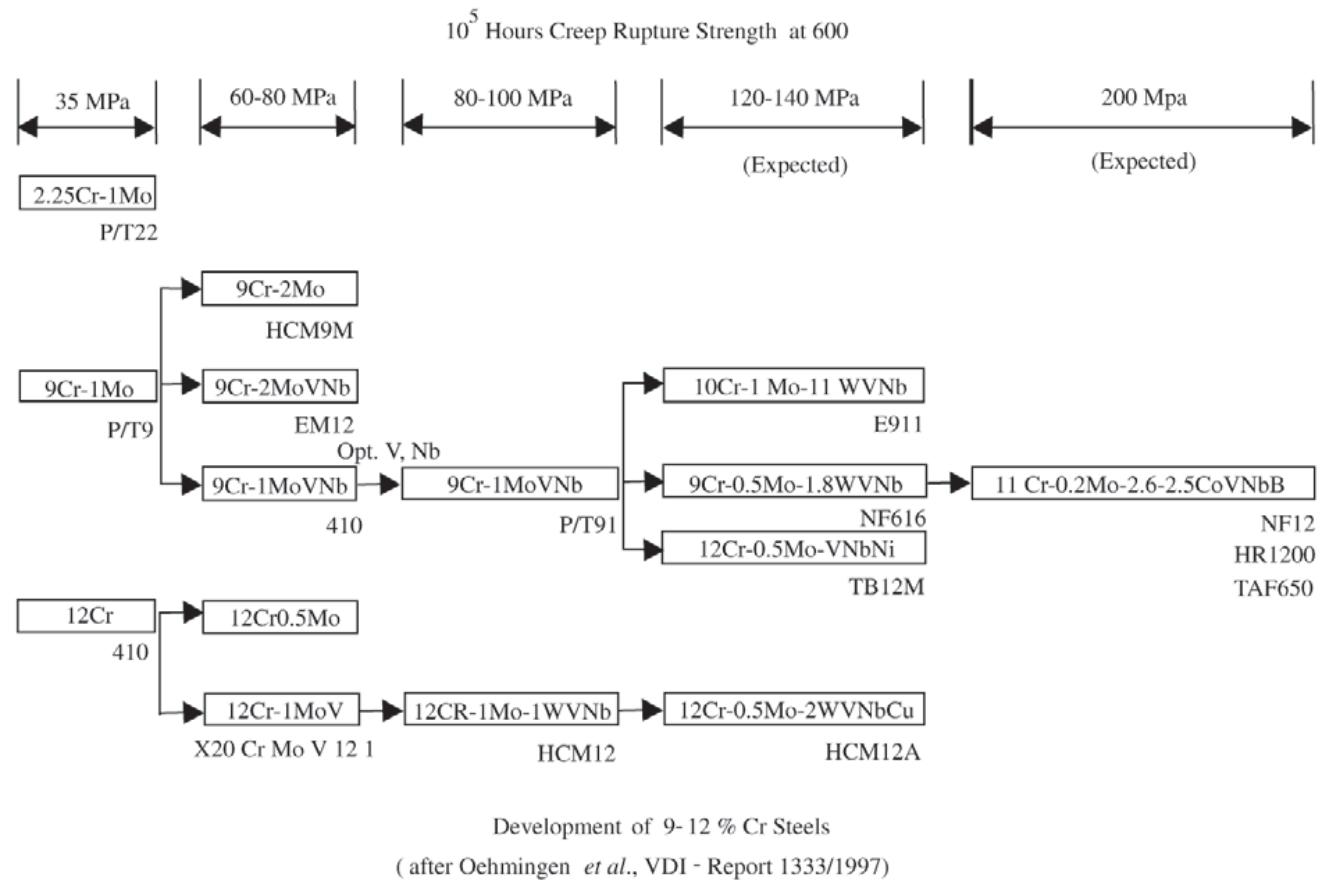

Figure 1. Development of modern $9-12 \% \mathrm{Cr}$ steels $^{1}$.

ence of water vapour. These nodules will finally cover the whole surface and lead to a continuous fast growing nonprotective iron rich oxide scale as shown in the lower part of Fig. 2. In the literature this effect is well known as "breakaway" oxidation which is also illustrated in the form of mass gain curves in Fig. 3 which summarises schematically the different forms of oxidation conceivable.

Due to the low margin of $\mathrm{Cr}$ against the critical $\mathrm{Cr}$ content these steels are very much endangered with regard to their long term oxidation resistance and their reliability. Therefore it is conceivable that even minor changes in the environment, in the surface conditions of a material or in the material composition itself or the effect of external stresses can significantly alter the oxidation behaviour. As indicated by several publications it may be first of all the water vapour content in the environment which has a particular influence on kinetics and scale structure during oxidation of these materials ${ }^{3-9}$. Water vapour is known to help with the formation of volatile chromium containing species, thus increasing the kinetics of chromium depletion in the metal subsurface zone. Therefore, if scale cracking occurs, be it due to cooling (e.g. under thermal cycling or due to plant inspection) or even under isothermal conditions as a consequence of scale growth stresses or by creep of the substrate breakaway oxidation may occur. Since the chromium content is so crucial for these steels ${ }^{2}$ even small amounts of additional alloying elements can have a sig- nificant influence on oxidation behaviour (e.g. Mn, Mo, $\mathrm{Si}, \ldots)$ in that they either influence the nucleation behaviour of the protective chromia scale (and by this also the healing behaviour of cracks) or the chromium depletion behaviour of the metal subsurface zone during oxidation.

Taking all these aspects into consideration the present work was started with the aim of clarification of the role of water vapour in the environment for oxidation behaviour, the kinetics of chromium subsurface zone depletion as a function of the water vapour content in the atmosphere, the role of scale growth stresses in the originally protective oxide, the role of creep stresses and the influence of additional alloying elements in the steels. The aim of this work was to accomplish a better understanding of the role of these parameters in particular with regards to the acceleration of oxidation and the time to breakaway.

\section{Experimental}

All in all nine different versions of $9 \% \mathrm{Cr}$ steel were investigated in the present work. Three of them were commercial or quasi-commercial versions of P91, E911, and Nf616. The latter one was supplied in a pre-commercial version, which had a lower silicon content than the presently used commercial version (now 0.3 to $0.4 \% \mathrm{Si}$ ). In addition six variants of the steel Nf616 with different silicon contents were investigated. The aim of the variation of the silicon content was to elucidate the role of silicon for 

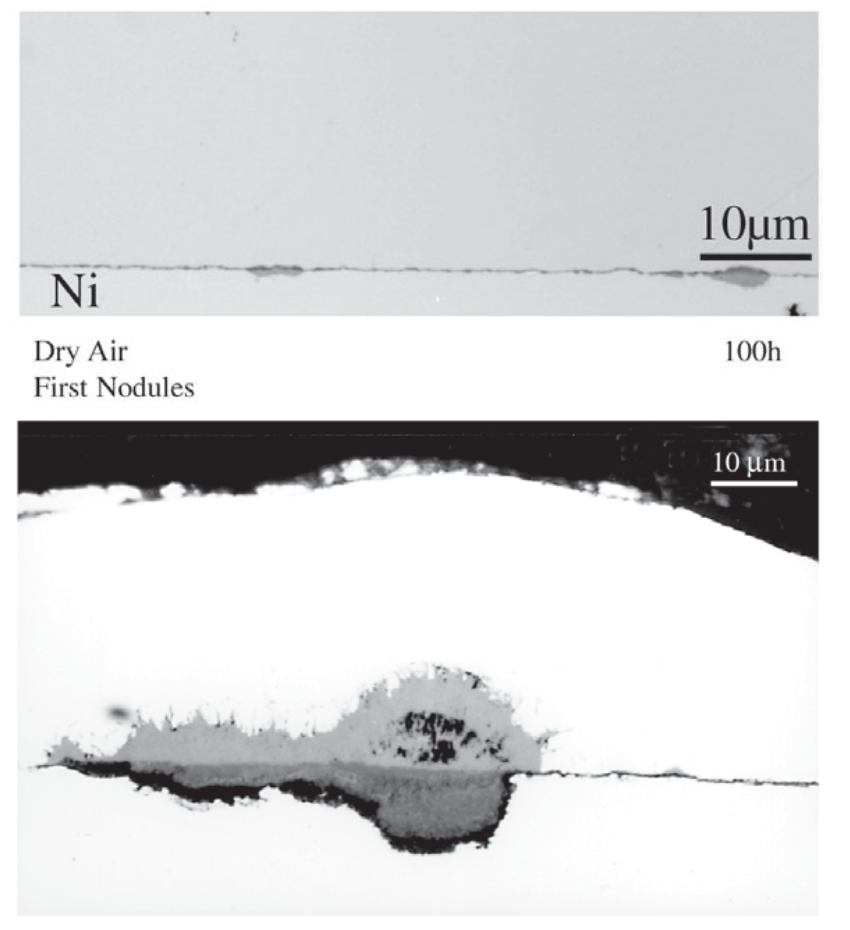

$$
10 \% \mathrm{H}_{2} \mathrm{O}
$$

Local Nodules

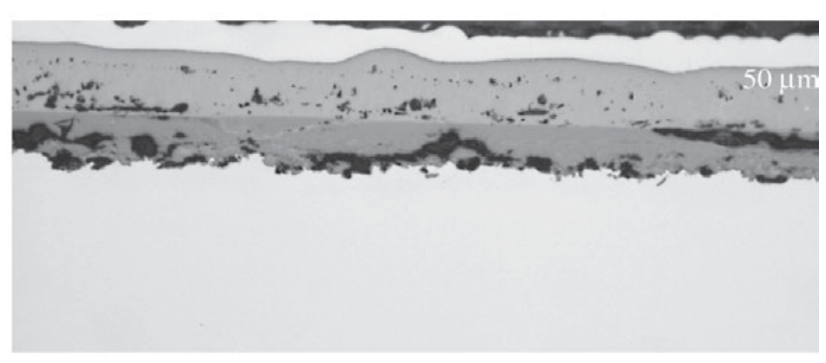

$10 \% \mathrm{H}_{2} \mathrm{O}$

Continues Thick Scale

(Post-Breakaway State)

Figure 2. Three steps of oxide scale formation starting with small nodules until thick continuous oxide layer formation for P91 at $650{ }^{\circ} \mathrm{C}$. oxidation in water vapour containing environments and for the time to breakaway oxidation. The composition of these materials is given Table 1 . It should be pointed out that the steel P91 had the highest silicon content of the commercial versions together with the highest chromium content of all alloys. It further contained the highest amount of molybdenum (which was similar to E911) and the highest nickel content. Contrary to the other materials investigated the P91 was free of tungsten. E911 contained less silicon than P91 but still significantly more than Nf616. In addition E911 had tungsten as an alloying element, which was however little more than half of the amount of that in Nf616 and its laboratory versions. The carbon content for the E911, P91 and Nf616 are also listed in Table 1, however, the carbon content of the laboratory variants of Nf616 is not known. While the commercial or quasi-commercial steels had been supplied by Forschungszentrum Jülich the different variants of Nf616 were received from Hitachi-Babcock, Japan in the form of laboratory melts.

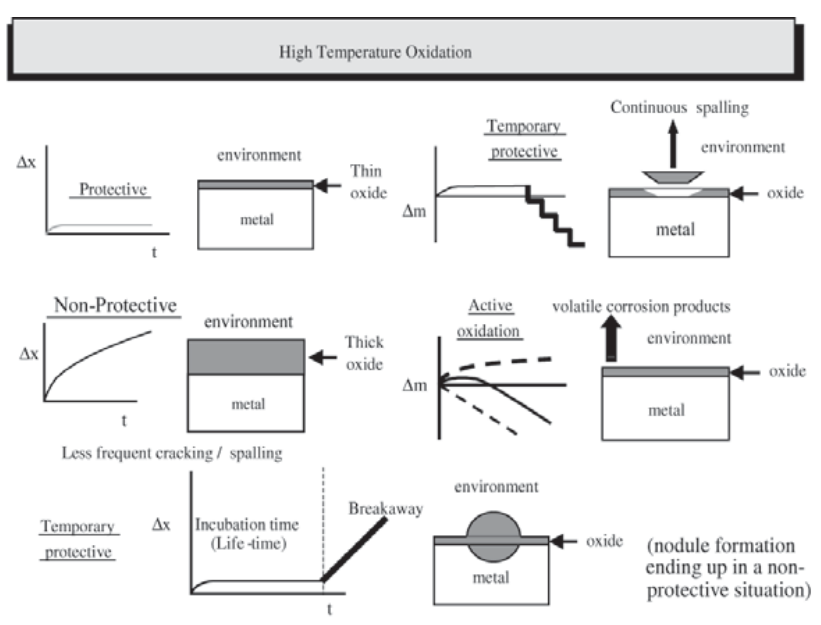

Figure 3. Schematic of the different types of oxidation behaviour.

Table 1. Composition of the Steels Investigated (in Mass).

\begin{tabular}{lcccccccc}
\hline Materials & Si & W & Mo & Cr & Mn & V & Ni & C \\
\hline E911 & 0.24 & 1.00 & 0.92 & 8.70 & 0.50 & 0.20 & 0.23 & 0.12 \\
P91 & 0.40 & 0.00 & 0.93 & 9.00 & 0.55 & 0.22 & 0.36 & 0.06 \\
Nf616 & 0.04 & 1.84 & 0.47 & 8.96 & 0.46 & 0.20 & 0.10 \\
Var1 & 0.02 & 1.78 & 0.49 & 8.65 & 0.51 & 0.20 & 0.01 & - \\
Var2 & 0.11 & 1.75 & 0.48 & 8.55 & 0.51 & 0.20 & 0.01 & - \\
Var3 & 0.25 & 1.68 & 0.48 & 8.62 & 0.51 & 0.20 & 0.01 & - \\
Var4 & 0.44 & 1.72 & 0.50 & 8.84 & 0.52 & 0.20 & 0.01 & - \\
Var5 & 0.57 & 1.72 & 0.51 & 8.98 & 0.53 & 0.21 & 0.01 & - \\
Var6 & 0.78 & 1.74 & 0.50 & 8.88 & 0.52 & 0.20 & 0.01 & - \\
\hline
\end{tabular}


From all these materials coupons of the size $20 \times 10 \times 2 \mathrm{~mm}$ were made with a surface finish of 1200 grit. These specimens were subjected to discontinuous oxidation testing at $650{ }^{\circ} \mathrm{C}$ for times up to $10000 \mathrm{~h}$. These tests were performed in dry synthetic air, synthetic air with $4 \%$ and synthetic air with $10 \%$ water vapour. The specimens were taken out after different oxidation times, the weight was determined and after the weight measurements the specimens were cross sectioned and investigated by metallographic and micro analytical investigations. For the laboratory versions of Nf616 the specimens were inserted again after the weight measurements and post experimental investigations were only performed after $10000 \mathrm{~h}$. Furthermore some creep test were performed in laboratory air for Nf616 and $\mathrm{P} 91$ at $650^{\circ} \mathrm{C}$. The load was chosen so that the creep rate in the secondary region was between $5 \times 10^{-8} \mathrm{~s}^{-1}$ and $2 \times 10^{-7} \mathrm{~s}^{-1}$. The tests were terminated at the beginning of the tertiary creep region. These tests were performed after preoxidation times of 0 to $3 \mathrm{~h}, 150 \mathrm{~h}, 500 \mathrm{~h}$ and $1000 \mathrm{~h}$ in order to determine the influence of the chromium content underneath the oxide scale on the healing properties of the materials. Besides metallography effort was put on the investigation of the scale composition and the composition of the metal subsurface zone (in particular $\mathrm{Cr}$ content) as a function of oxidation time using electron probe micro analysis (EPMA). In addition to reveal whether evaporation of certain species had taken place due to the presence of water vapour energy depressive X-ray (EDX) and UV absorption spectroscopy was performed with the condensed products at the end of the tube of the test equipment. In the present research project the deflection test mono-facial oxidation (DTMO) method was used for the determination of the intrinsic growth stresses. This test method allows the in-situ measurements of intrinsic growth stresses by a deflection test of thin metal foils. The testing set up is combined with acoustic emission measurements to detect possible stress relief mechanisms like microcracking. This method was successfully applied to the model system nickel oxide on nickel in $^{10}$ and for alumina on CoNiCrAlY bond coats in ${ }^{11}$, where the test principles and procedures are described in detail. The test steel specimen used for DTMO are thin metal foil with the dimensions $50 \times 5 \times 0.25 \mathrm{~mm}$. One side of the foil is protected against oxidation by preoxidation to assure that only the unprotected side of the specimen oxidises. During oxidation the growth stresses produce a bending moment in the thin foil, where the measured foil deflection can in turn be used for the determination stress.

\section{Results}

\subsection{Oxidation kinetics}

The results of the weight change measurements for the commercial steels are summarized in Figs. 4-6. For all of

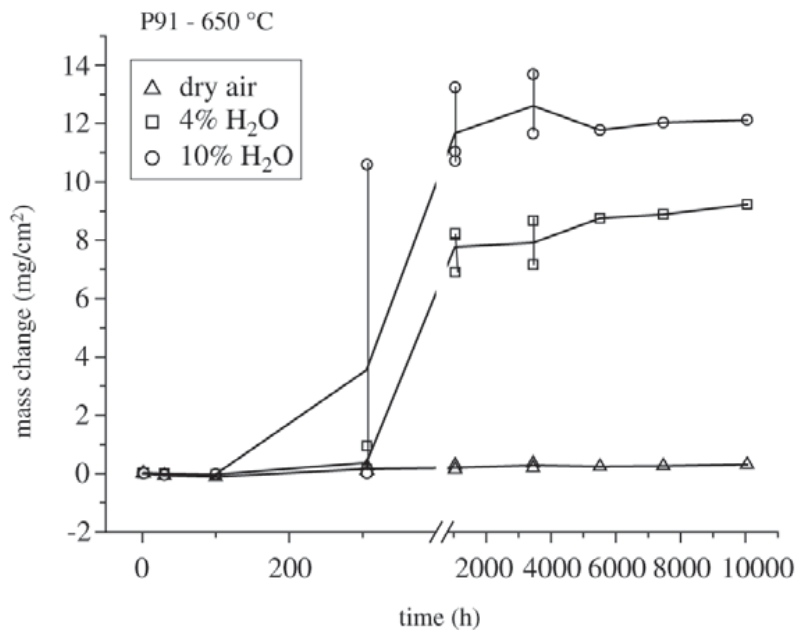

Figure 4. Results of mass change measurement as a function of time for steel P91 at $650{ }^{\circ} \mathrm{C}$ in different environments.

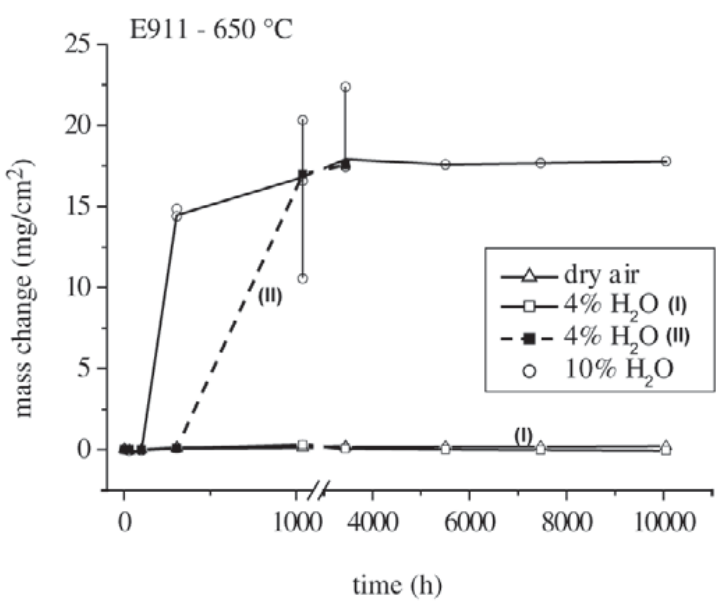

Figure 5. Results of mass change measurement as a function of time for steel E911 at $650{ }^{\circ} \mathrm{C}$ in different environments.

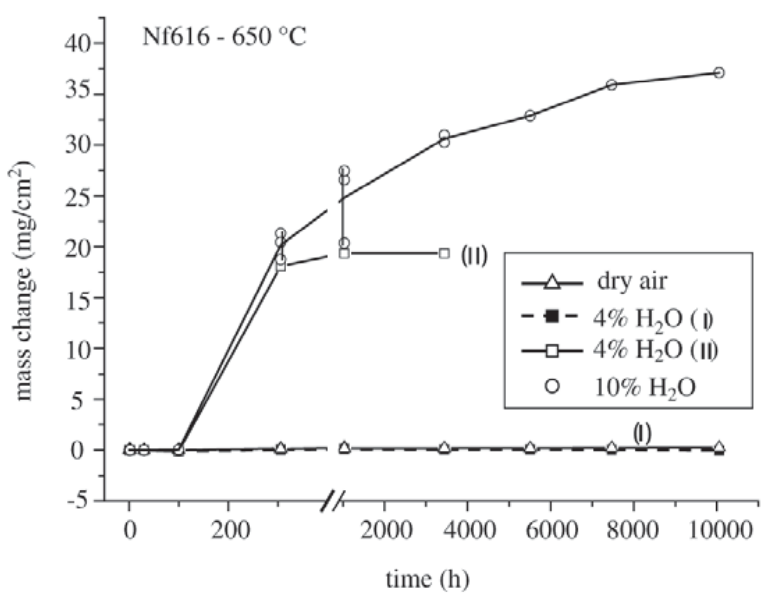

Figure 6. Results of mass change measurement as a function of time for steel Nf616 at $650{ }^{\circ} \mathrm{C}$ in different environments. 
these steels no breakaway occurs in dry synthetic air for times up to $10000 \mathrm{~h}$. Also the laboratory versions showed no breakaway, see examples in Figs. 7-9. This can be explained by the formation of a thin protective oxide scale, which mostly consists of chromium oxide but may also contain significant amounts of manganese in its outer part, see example for P91 after $10000 \mathrm{~h}$ in Fig. 10. Although P91 contains a significant amount of silicon no continuous silica partial layer was observed under this condition. Only discrete silica islands were present at the oxide metal interface. Iron was not part of these oxide scales. When $4 \%$ water vapour is added to the atmosphere the picture becomes less uniform. In the case of P91 breakaway occurred in all cases (always 3 specimens were tested at the same time) between $300 \mathrm{~h}$ and $1000 \mathrm{~h}$, see Fig. 4. For E911 the situation was somewhat different in that some specimens did

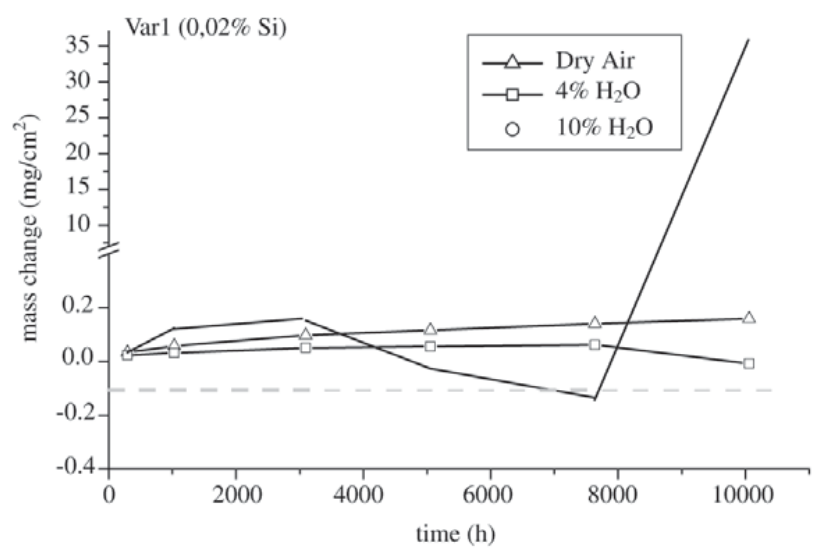

Figure 7. Results of mass change measurement as a function of time for Variation 1 of $\mathrm{Nf6} 616$ at $650{ }^{\circ} \mathrm{C}$ in different environments.

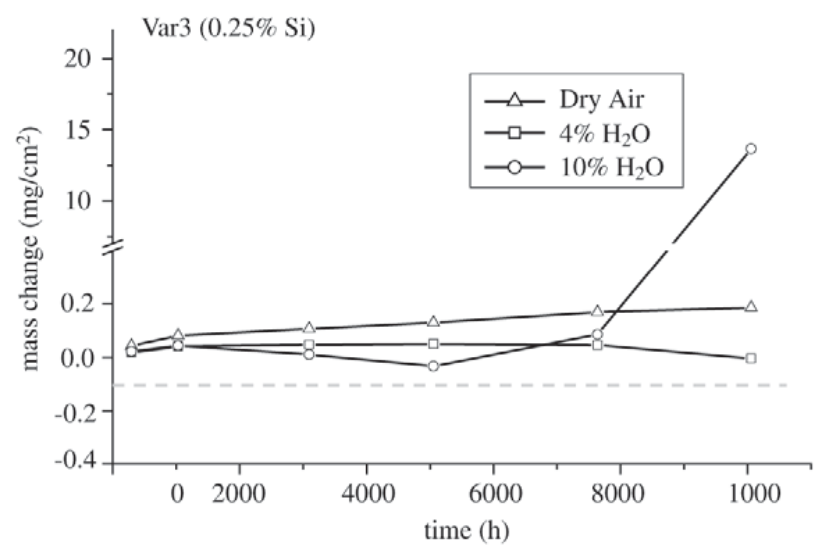

Figure 8. Results of mass change measurement as a function of time for Variation 3 of $\mathrm{Nf} 616$ at $650{ }^{\circ} \mathrm{C}$ in different environments. not show breakaway under $4 \%$ water vapour while others revealed a similar behaviour as P91 (e.g. breakaway between $300 \mathrm{~h}$ and $1000 \mathrm{~h}$ ), see Fig. 5. For the pre-commercial version of Nf616 breakaway did again either not occur at all during the testing period of $10000 \mathrm{~h}$ or it occurred between 100 and 300 h, see Fig. 6. Surprisingly not any breakaway at all was observed for any of the laboratory versions of Nf616 when the atmosphere contained $4 \%$ water vapour, compare examples in Figs. 7-9. There was, however, a slight mass decrease over time, which became particularly evident due to the long testing times of $10000 \mathrm{~h}$. While the oxide scale on these laboratory versions still revealed a composition and structure comparable to those in dry air there was a completely different structure for those commercial steels where breakaway had occurred, see e.g. Fig. 11. This scale composition and structure is similar for P91, E911 and Nf616 after breakaway and consists of a thick oxide scale of iron oxides in the outer part and iron chromium oxide in its inner part. Interestingly along the scale/metal interface a chromium rich thin layer had formed, which should have a good barrier effect. Indeed when looking at Figs. 4-6 it becomes evident that soon after breakaway a kind of repassivation occurs slowing down the oxidation rates to a level not too far away from those in dry air. This behaviour can be assigned to the formation of a repassivation layer underneath the thick iron rich oxide formed after breakaway. It should be pointed out that breakaway starts at certain positions of the surface by the formation of local nodules, see Fig. 2. These fast growing nodules start to cover large parts of the surface and grow together finally ending up in the continuous thick oxide scale shown as an example for these steels after $10000 \mathrm{~h}$ in Fig. 2. Increasing the water vapour content to $10 \%$ results in breakaway for all steels investigated, see Figs. 4-9. The only difference was that for the commercial or pre-commercial type

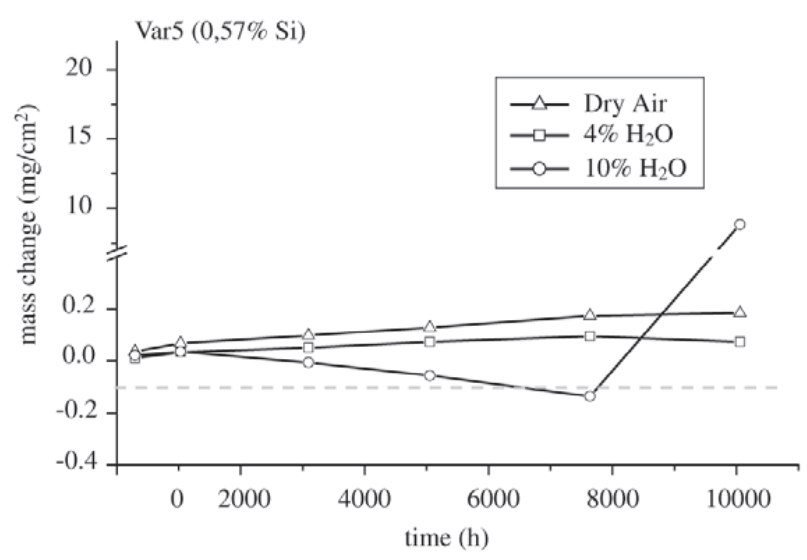

Figure 9. Results of mass change measurement as a function of time for Variation 5 of $\mathrm{Nf6} 616$ at $650{ }^{\circ} \mathrm{C}$ in different environments. 

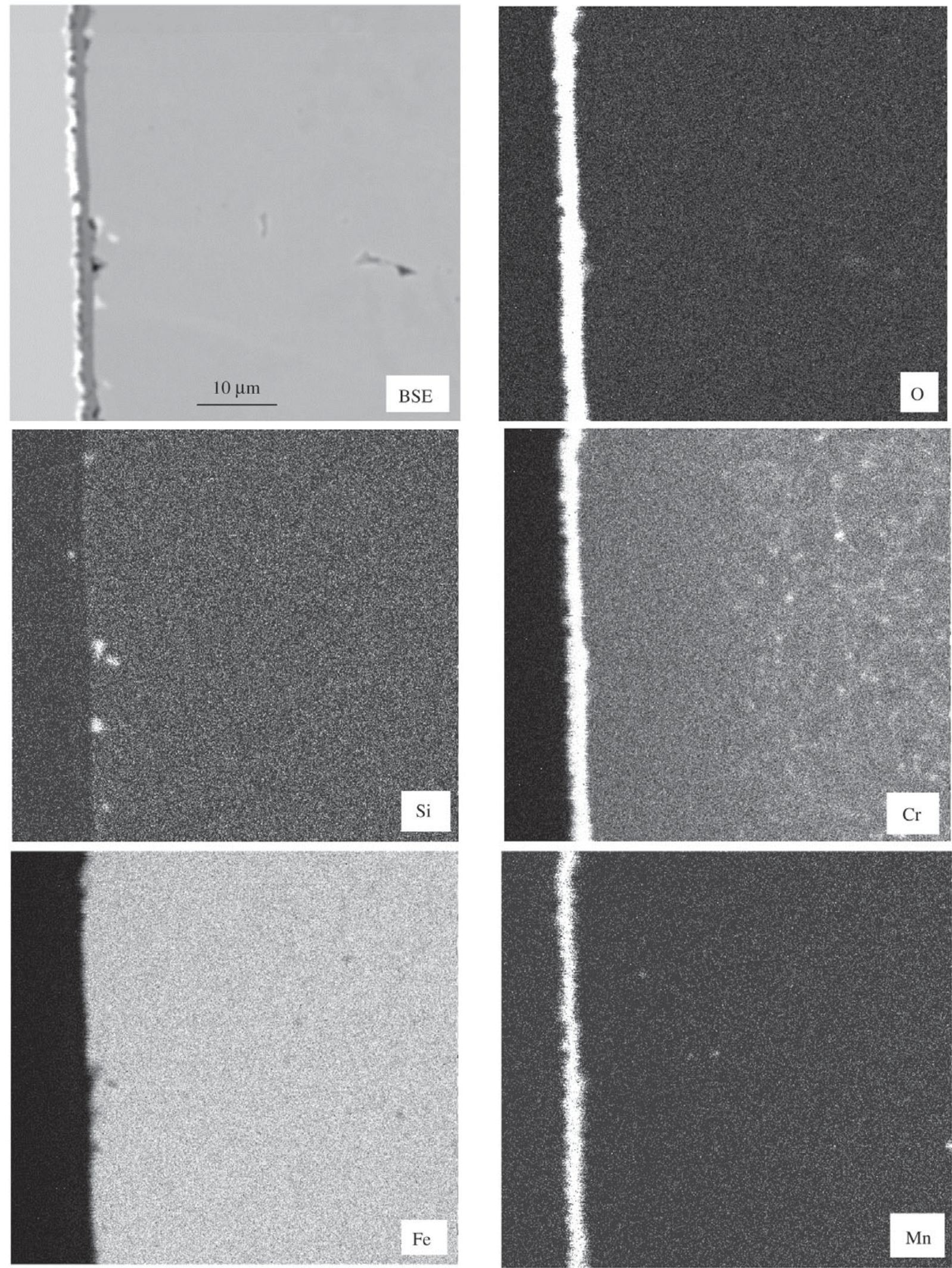

Figure 10. Elemental distribution maps for $\mathrm{P} 91$ at $650{ }^{\circ} \mathrm{C}$ in dry synthetic air after $10000 \mathrm{~h}$. 

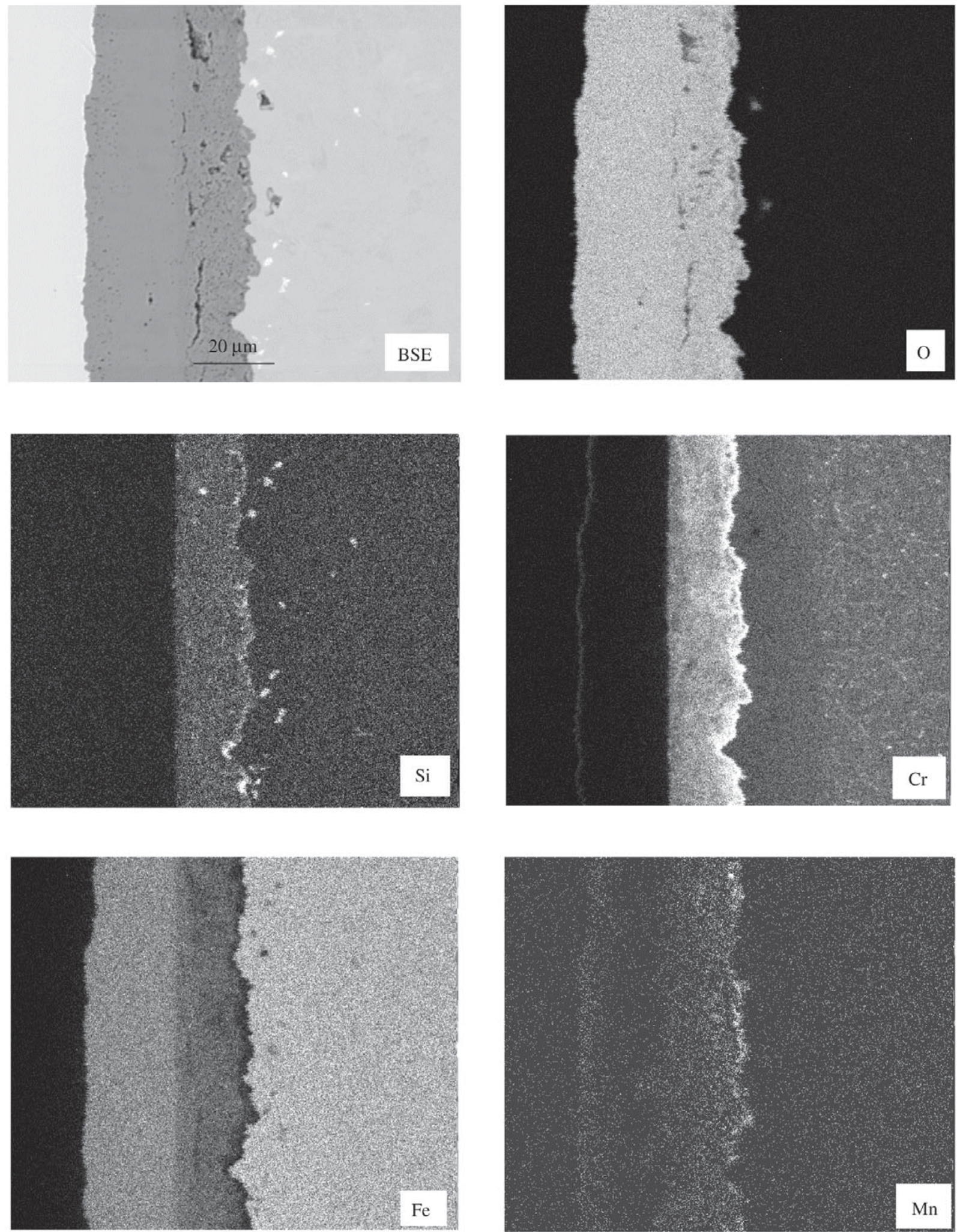

Figure 11. Elemental distribution maps for $\mathrm{P} 91$ at $650{ }^{\circ} \mathrm{C}$ in air with $4 \% \mathrm{H}_{2} \mathrm{O}$ after $10000 \mathrm{~h}$. 
steels breakaway occurred between 100 and $300 \mathrm{~h}$ while for the laboratory versions of Nf616 in several cases breakaway was found only after more than 7,500 h. Surprisingly even the variant of Nf616 with $0.02 \%$ silicon showed such good oxidation resistance while the version with the slightly higher amount of $0.11 \% \mathrm{Si}$ exhibited immediate breakaway ${ }^{12}$. The version with $0.44 \mathrm{Si}$ was somewhat in between with breakaway times between 3,500 and 5,500 $\mathrm{h}^{12}$. In all these cases a continuous mass decrease had taken place before breakaway started. Again there was a significant repassivation effect observed in the mass change kinetics after breakaway for all the materials tested, which is explained by repassivation in the form of the formation of a chromium rich inner oxide layer at the scale/metal interface.

EDX and UV absorption spectroscopy of condensed products at the end of the tube in the furnace revealed chromium rich species in the water vapour containing environments. The condensed products had a yellow colour, EDX analysis of the as deposited crystals revealed Cr-rich species. After EDX measurements the furnace tube ends were washed with distilled water. The wash solution was then tested by UV-flame spectroscopy, where the UV absorption spectra from the wash solution was compared to the spectra of standard potassium chromate and potassium dichromate solutions. The spectra from the wash solution, the potassium chromate solution and the potassium dichromate solution have characteristic absorption peaks at 349, 371, and $352 \mathrm{~nm}$, respectively. Consequently the $\mathrm{Cr}^{+6}$ ion is present in the condensed products found in the ends of the furnace tube. The amount of this condensed species in- creased when increasing the water vapour content from 4 to $10 \%$. In order to find out which volatile species could be present under the conditions of these investigations CHEMSAGE ${ }^{13}$ calculations were performed for an environment consisting of air with $10 \%$ water vapour at $650{ }^{\circ} \mathrm{C}$. As solid phases in these calculations $\mathrm{Cr}, \mathrm{Cr}_{2} \mathrm{O}_{3}, \mathrm{Mo}, \mathrm{W}$ and $\mathrm{Si}$ have been regarded (in 1 mol quantities), which represent the major alloying elements and the protective scale on the surface of these steels. The results of these calculations are summarized in column 2 of Table 2 . The highest partial pressures of metal containing species are developed by $\mathrm{MoH}_{2} \mathrm{O}_{4}$ and $\mathrm{CrH}_{2} \mathrm{O}_{4}$ and indeed $\mathrm{Cr}$-rich species are found by UV-spectroscopy in the cold parts of the furnace. In the literature occasionally a partial pressure of $10^{-9}$ bar is taken as a lower limit for measurable evaporation of species from an oxidation reaction ${ }^{15}$. Taking this criterion it is $\mathrm{MoH}_{2} \mathrm{O}_{4}$ and $\mathrm{CrH}_{2} \mathrm{O}_{4}$ which should evaporate from the specimen surfaces. Still there is a difference in partial pressures of more than 3 orders of magnitudes between $\mathrm{MoH}_{2} \mathrm{O}_{4}$ and $\mathrm{CrH}_{2} \mathrm{O}_{4}$. However since molybdenum is present in the alloys in a much smaller amount than chromium and since further more it is only the chromia scale which is directly exposed to the environment it can be assumed that mainly $\mathrm{CrH}_{2} \mathrm{O}_{4}$ is responsible for the observed continuous mass decrease. This is further confirmed by the observation that the mass decrease rate is rather slow and mass loss only becomes evident after significant oxidation times, which means $1000 \mathrm{~h}$ and more. Therefore the evaporation rates seemed to be relatively low. Moving back to Figs. 7 to 9 it appears as if a critical amount of evaporation of about $-0.1 \mathrm{mg} / \mathrm{cm}^{2}$ can be taken as a criterion for the beginning of breakaway.

Table 2. Partial pressures of gaseous species in air with $10 \% \mathrm{H}_{2} \mathrm{O}$ at $650{ }^{\circ} \mathrm{C}$ in the presence of $\mathrm{Cr}, \mathrm{Cr}_{2} \mathrm{O}_{3}, \mathrm{Mo}$, W and $\mathrm{Si}$ as solid phases. Calculations by the computer programme CHEMSAGE ${ }^{13,14}$

\begin{tabular}{|c|c|c|c|}
\hline Compound & $\begin{array}{l}\text { Partial pressure } \\
\text { (bar) }\end{array}$ & $\begin{array}{c}\text { Evaporation rate } \\
\left(\mathrm{mg} / \mathrm{cm}^{2} \mathrm{~s}\right) \\
\alpha_{1}=1\end{array}$ & $\begin{array}{c}\text { Evaporation rate } \\
\left(\mathrm{mg} / \mathrm{cm}^{2} \mathrm{~s}\right) \\
\alpha_{1}=2.0 \times 10^{-4}\end{array}$ \\
\hline $\mathrm{N}_{2}$ & $7.3 \times 10^{-1}$ & & \\
\hline $\mathrm{O}_{2}$ & $1.8 \times 10^{-1}$ & & \\
\hline $\mathrm{H}_{2} \mathrm{O}$ & $9.2 \times 10^{-2}$ & & \\
\hline NO & $1.1 \times 10^{-5}$ & & \\
\hline $\mathrm{MoH}_{2} \mathrm{O}_{4}$ & $5.5 \times 10^{-6}$ & 0.30 & $6.1 \times 10^{-5}$ \\
\hline $\mathrm{HO}$ & $2.1 \times 10^{-8}$ & & \\
\hline $\mathrm{CrH}_{2} \mathrm{O}_{4}$ & $1.1 \times 10^{-9}$ & $5.2 \times 10^{-5}$ & $1.0 \times 10^{-8}$ \\
\hline $\mathrm{HO}_{2}$ & $3.0 \times 10^{-10}$ & & \\
\hline $\mathrm{WH}_{2}^{2} \mathrm{O}_{4}$ & $5.5 \times 10^{-12}$ & $3.8 \times 10^{-7}$ & $7.6 \times 10^{-11}$ \\
\hline $\mathrm{CrO}_{3}$ & $9.8 \times 10^{-12}$ & $4.3 \times 10^{-7}$ & $8.5 \times 10^{-11}$ \\
\hline $\mathrm{O}$ & $5.2 \times 10^{-12}$ & & \\
\hline $\mathrm{H}_{2}$ & $1.6 \times 10^{-12}$ & & \\
\hline others & $<10^{-13}$ & & \\
\hline
\end{tabular}


Breakaway starts once this value has been reached (in Fig. 8 one has to extrapolate the two branches of the curve before and after breakaway and take the intersection of these extrapolated lines). This could be an indication that by evaporation a critical amount of chromium depletion is reached in the metal subsurface zone, which in combination with scale cracking processes and the exposure of the strongly depleted metal subsurface zone to the environment results in the formation of non-protective oxide and, thus, breakaway oxidation.

As a first step, rough calculations of the volatilisation rates have been made using the Hertz-Langmuir Equation ${ }^{16}$,

$$
k_{i}=44 \cdot 3 \alpha_{i} p_{i}\left(M_{i} / T\right)^{0.5}
$$

where $\mathrm{k}_{\mathrm{i}}, \mathrm{p}_{\mathrm{i}}$ and $\mathrm{M}_{\mathrm{i}}$ are the volatilisation rate, vapour pressure and molecular weight of the evaporating species. The $\alpha_{1}$ in known as the evaporation rate constant and is usually equal to about unity when the solid and gaseous species contain the same molecules. The calculated volatilisation rates for $\alpha_{1}=1$ are in column 3 of Table 2, which represent the maximum theoretical volatilisation rates of the metal containing species. However, for the $\mathrm{Cr}$ steels under investigation the solid and gaseous species do not contain the same molecules and $\alpha_{i}$ should be less than unity. Calculated volatilisation rates for the arbitrarily chosen value of $\alpha_{1}=2.0 \times 10^{-4}$ are in column 4 of Table 2 . These volatilisation rates can be used in Eq. 3 for the determination of the approximate weight change in the oxidation environment containing $10 \%$ water vapour, where Eq. 2 is the oxidation kinetics for the dry atmosphere.

$$
\begin{aligned}
& m=k_{p} t^{0.5} \\
& m=k_{p} t^{0.5}-k_{i} t
\end{aligned}
$$

Result are plotted in Fig. 12, where the $\mathrm{k}_{\mathrm{p}}$ value used is $3.4 \times 10^{-5} \mathrm{mg} / \mathrm{cm}^{2} \mathrm{~s}^{0.5}$. The open triangles represent the oxidation behaviour in the dry atmosphere, where the values plotted in Fig. 12 match the measured values in Figs. 7-9. When the evaporation of $\mathrm{CrO}_{3}$ is factored into the mass change calculation (open circles in Fig. 12) by using Eq. 3 and the evaporation rate in column 4 of Table 2 it is seen that there is no weight loss due to the volatilisation of $\mathrm{CrO}_{3}$. This is consistent with the conventional rule that $\mathrm{CrO}_{3}$ evaporation does not play a substantial role in the oxidation behaviour of chromia formers below temperatures of $1000{ }^{\circ} \mathrm{C}$ (see ref 16). When the evaporation of $\mathrm{CrH}_{2} \mathrm{O}_{4}$ is taken into consideration again by using Eq. 3 and the evaporation rate of $\mathrm{k}_{\mathrm{i}}=1.0 \times 10^{-8}$ from Table 2 the solid squares in Fig. 12 show a substantial weight loss, where the calcu-

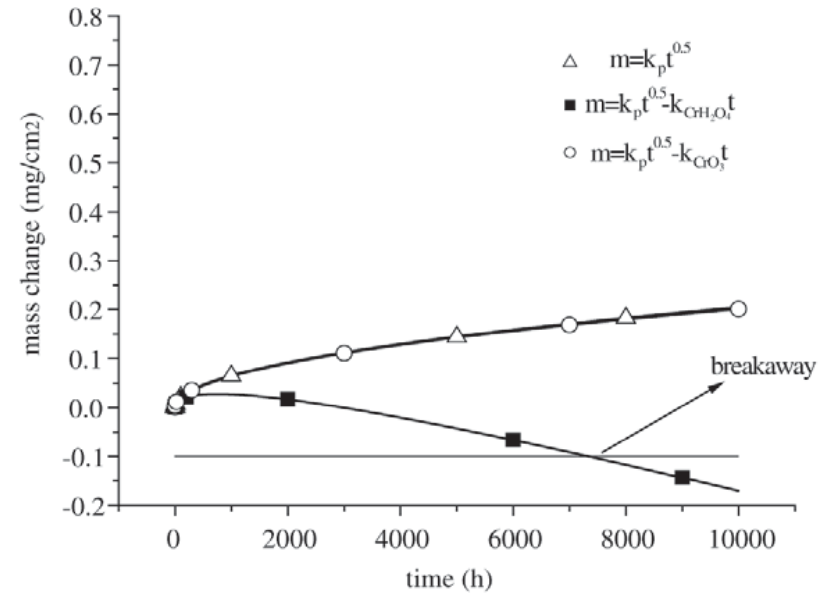

Figure 12. Results of mass change calculations as a function of time at $650{ }^{\circ} \mathrm{C}$. The calculations are based on Eqs. 2 and 3.

lated behaviour is quite similar to the measured values in Figs. 7-9. Additionally, in Fig. 12 the critical amount of weight loss of about $-0.1 \mathrm{mg} / \mathrm{cm}^{2}$ due to the evaporation of $\mathrm{CrH}_{2} \mathrm{O}_{4}$ can be taken as a criterion for the beginning of breakaway, where the origin of this critical weight loss may be due to $\mathrm{Cr}$ depletion in the subsurface directly underneath the oxide scale (see the next section).

The above calculations predict, for the laboratory variants of Nf616, that if the water vapour content is increased the partial pressure and the evaporation rate of $\mathrm{CrH}_{2} \mathrm{O}_{4}$ would also increase. Consequently, Eq. 3 shows that the time required to produce the critical weight loss and time to breakaway should decrease. Increasing the steels $\mathrm{Cr}$ content would increase the critical weight loss value and in turn increase the time to breakaway.

\subsection{Subsurface composition}

The results from the measurement of the $\mathrm{Cr}$ contents directly underneath the oxide scale in the metal subsurface zone as a function of oxidation time are given exemplarily for P91 in Fig. 13. For the other materials the curves are very similar. In all cases a steep decrease of the chromium content occurs at the beginning of oxidation. In dry synthetic air this decrease is always less marked than in the water vapour containing atmospheres. Only at scale positions where a few nodules had formed during early oxidation in dry air the chromium content had decreased more significantly (see e.g. Fig. 13 top "thick scale" in dry air). After the initial steep decrease the chromium content falls slowly but in the protective parts of the scale no increase occurs again during the testing time of $10000 \mathrm{~h}$. For the water vapour containing atmospheres the situation is entirely different. The initial decrease is much steeper and in 
particular at $10 \%$ water vapour it falls down to values as low as $4.2 \%$ (Nf616). After this decrease the chromium content increases again, in some cases significantly, see Fig. 13. This is a further indication of the mechanism of the
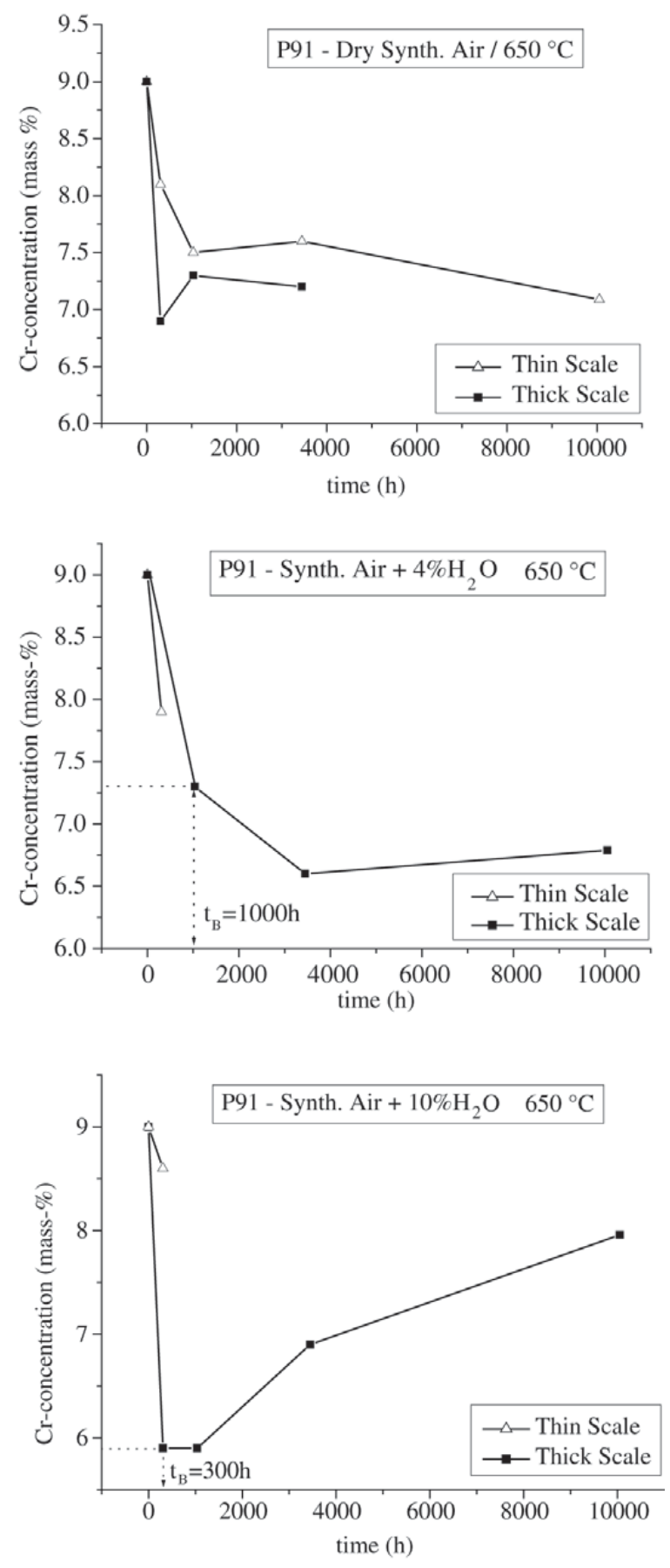

Figure 13. Cr-concentration directly underneath the oxide scale as a function of oxidation time for $\mathrm{P} 91$ at $650{ }^{\circ} \mathrm{C}$ in 3 different environments (results of EPMA-measurements). repassivation effect described earlier in this paper. Breakaway $\left(t=t_{B}\right)$ usually occurred when the chromium content had fallen to values below 6-7\%. Plotting the minimum chromium concentration, which can occur in the oxidation period of $10000 \mathrm{~h}$ as a function of the water vapour content in the environment leads to Fig. 14. This figure clearly indicates that with increasing water vapour there is a tendency of a more pronounced chromium depletion in the metal subsurface zone. While E911 and Nf616 seemed to fall into one common scatter band with the exception that at $10 \%$ water vapour E911 seems to be slightly better than Nf616 it is the steel P91 that shows a significantly lower decrease in the chromium content during oxidation. As a first guess this difference in depletion behaviour may be assigned to the different silicon contents in the materials, where P91 had the highest amount of silicon while Nf616 was almost silicon free. Possibly in particular at $10 \%$ water vapour silicon may play an increased role with regard to impeding chromium depletion in the metal subsurface zone by evaporation of chromium containing species. This tendency seems to be further confirmed by Fig. 15 where the relative amount of chromium was plotted as a function of the silicon content after $10000 \mathrm{~h}$ of oxidation for the 6 laboratory versions and the pre-commercial version of Nf616. With the exception of variant 1 and one experiment of variant 2 in $10 \%$ water vapour there seems to be a clear tendency of a decreasing depletion kinetics with regard to chromium in the metal subsurface zone with increasing silicon content. The reason for the improved behaviour of variant 1 compared to the other variants is not clear and the same relates to the specimen of variant 2 in $10 \%$ water vapour that revealed a behaviour which fell out of the general trend. What is also indicated by Fig. 15 is that the effect of silicon evidently is first of all present in the case of

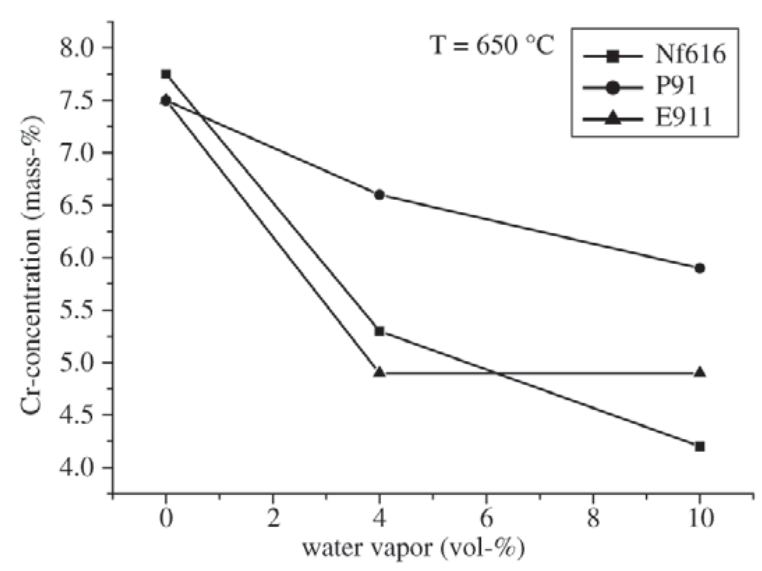

Figure 14. Minimum of Cr-concentration directly underneath the oxide scale as a function of the water vapour content at $650{ }^{\circ} \mathrm{C}$ after $10000 \mathrm{~h}$. 


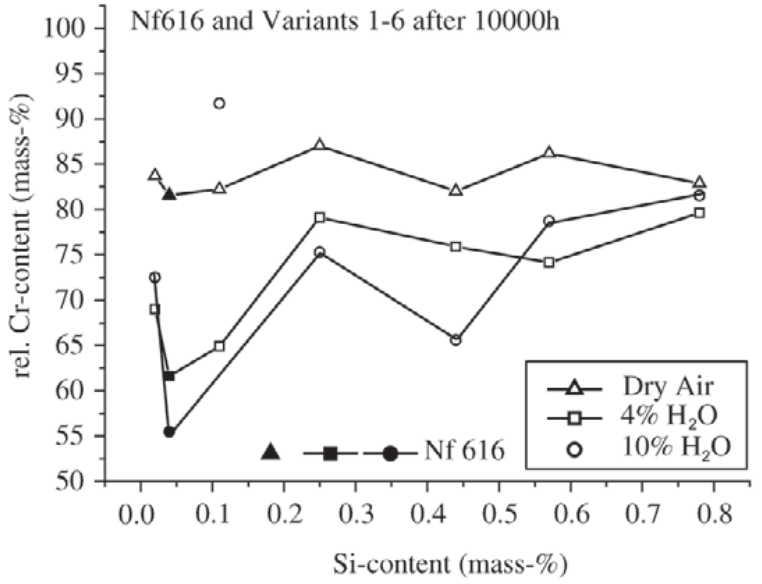

Figure 15. Relative amount of $\mathrm{Cr}$ underneath the oxide scale as a function of the silicon content after $10000 \mathrm{~h}$ for 6 laboratory versions and the pre-commercial version of $\mathrm{Nf} 616$ at $650{ }^{\circ} \mathrm{C}$ in different environments $(100 \%=9 \% \mathrm{Cr})$.

water vapour in the environment. In dry air no general tendency as a function of the silicon content could be found.

\subsection{Scale growth stresses}

The results from oxide scale stress measurements in dry air and humid air by the DTMO method which is described elsewhere ${ }^{10,11}$ are shown in Fig. 16 for the example of P91. Further detailed investigations on scale stresses in these materials and results from acoustic emission measurements are reported in ref. 2.

Taking all these results together the highest stresses are revealed by the scales on P91 and E911. In particular the scale on E911 shows high stresses over most of the oxidation period. The stresses on Nf616 are significantly lower reaching values of about $-400 \mathrm{MPa}$ at maximum while in the other cases the stresses may be as high as $-1200 \mathrm{MPa}$. Thus, there seems to be a general tendency that stresses in the oxide scale on Nf616 at least in air without additional water vapour are significantly lower than those on the other two materials. Switching to water vapour in the environment increases the scale stresses significantly, see example of P91 in Fig. 16. This is also confirmed by an increased acoustic emission activity in humid environment ${ }^{2}$ indicating increased cracking or spalling of the oxide. This is regarded as an important observation as it indicates that breakaway oxidation indeed should be the consequence of the interaction between chromium depletion in the metal subsurface zone and cracking processes in the originally protective oxide scale allowing direct contact between depleted subsurface zone and oxidant. As a further observation it was found that the amount of acoustic emission activity was significantly higher for $\mathrm{P} 91$ than for $\mathrm{Nf} 616^{2}$. As a

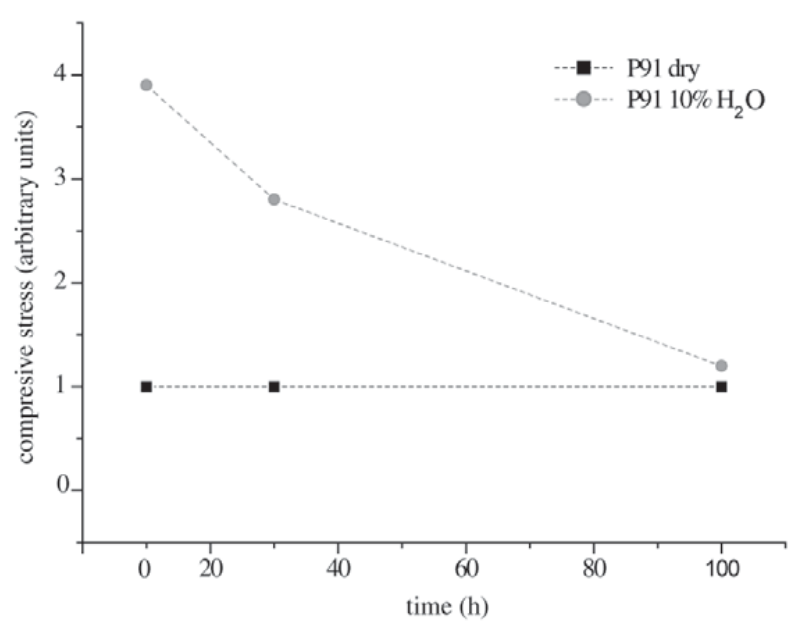

Figure 16. Relative level of the oxide scale stresses for P91 in dry synthetic air and air with $10 \% \mathrm{H}_{2} \mathrm{O}$.

consequence significantly more cracking should take place in the scales on P91, which would counteract the positive effect of the higher silicon content in the metal subsurface zone compared to Nf616.

\subsection{Oxidation under superimposed creep}

Mass change measurements are not possible for creep specimens, so that the influence of creep on oxidation had to be recorded by differences in the scale morphology, i.e. proportion of fast growing nodules compared to slow growing thin parts of the scales. Since the most interesting parameter was preoxidation time (leading to different amounts of Cr-depletion in the metal subsurface zone) the creep tests were started after 0 to 3,150 and $500 \mathrm{~h}$ of isothermal preoxidation in dry air. These experiments were only performed for P91 and Nf616. There are only very few nodules of faster growing oxide on $\mathrm{P} 91$ with the surface covered mainly by a very thin oxide scale. No effect of preoxidation was observed. A more significant influence of creep on oxidation was found for Nf616. The results on nodule formation are summarised in Fig. 17. For Nf616 the number of nodules per unit area increases with preoxidation time. There is no such effect for P91 which shows a very small number of nodules independent of preoxidation time.

The stationary creep rates in the tests were between $5 \times 10^{-8}$ and $2 \times 10^{-7} \mathrm{~s}^{-1}$. The primary creep period lasted up to about $1 \%$ strain, the secondary creep period until about $5 \%$ strain and the tests were terminated in the tertiary creep period after about $8 \%$ strain. The overall duration of the creep tests without preoxidation time was about $100 \mathrm{~h}$. According to the literature (see data presented in ref. 17) the critical tensile strain for oxide scale cracking of chromia scales lies in the order of $0.1-0.5 \%$ depending on the size 


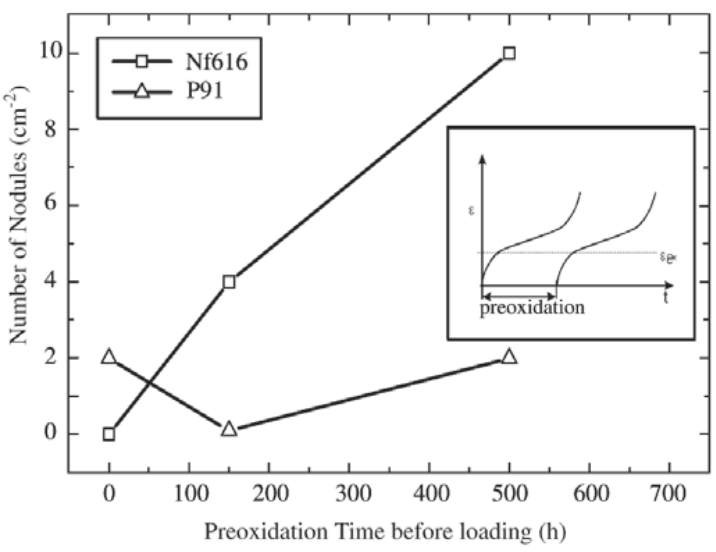

Figure 17. Number of iron rich fast growing nodule lines at scale cracks per square centimetre after the creep tests as a function of preoxidation time.

of physical defects in the oxide. For the present creep tests this means that the scales must have cracked and healed continuously during the loading period.

Interestingly the higher Si-content in P91 seems to offer some advantage over Nf616 with regard to protective healing of potential scale cracks. During creep Nf616 in dry air changes into breakaway behaviour while P91 does not. Thus, silicon seems to help to restore the protective effect of the scale during creep by accelerated crack healing (possibly accelerated nucleation of protective oxide). While in water vapour the positive Si-effect may be spoilt by the presence of Mo (compare also table 2) this does not seem to play a role in dry environment.

\section{Conclusions}

The results of the present investigations show that water vapour can have a significant influence on the oxidation behaviour of $9 \% \mathrm{Cr}$ steels. For this influence there may be several reasons. The first is that measurable evaporation of chromium containing species occurs in the presence of water vapour, which is increased with increasing content of $\mathrm{H}_{2} \mathrm{O}$ in the environment. This evaporation leads to a slow continuous mass decrease of the specimens as long as they have protective oxide scales mainly consisting of chromia. The result of this evaporation is a significant decrease of the chromium concentration in the metal subsurface zone in combination with a chromium decrease, which is directly related to chromia formation by simple oxidation.

The second reason is that evidently all the scales exhibit significant scale growth stresses even under isothermal conditions, which may reach critical values to induce scale (micro-)cracking and subsequent scale crack healing. The process evidently can be stimulated by the presence of water vapour since higher scale stresses and increased acoustic emission are observed under these conditions. There is a general tendency that $\mathrm{P} 91$, which contains a higher amount of molybdenum shows more acoustic emission activity (and thus cracking activity) than the low molybdenum containing Nf616 materials. Since as a result of thermodynamic calculations molybdenum can form highly volatile hydroxyl species under these conditions it can be suspected that these increase the tendency to scale cracking and may even have an impeding effect on scale healing.

Quite clearly the results showed that the occurrence of breakaway is the result of cracking processes in the oxide scale in combination with a strong $\mathrm{Cr}$ subsurface zone depletion. Breakaway is shifted to shorter times with increasing water vapour content in the environment.

During creep the protective oxide scales crack leading to breakaway for the silicon free Nf616. No breakaway is observed for P91 which is attributed to the higher Si-content helping with protective scale crack healing possibly by the facilitation of nucleation of protective oxide.

The results of the present investigations indicate that silicon furthermore seems to retard breakaway in the presence of water vapour in the environment and may even help with the repassivation effect observed after breakaway.

The effect of manganese has not been investigated directly in the present work but from other investigations it can be expected that manganese can have a positive effect in water vapour containing environments by slowing down the evaporation rate of chromium containing hydroxyl species due to the formation of an outer Cr-Mn-spinel layer ${ }^{18}$.

Variation of tungsten in the alloys did not show any effect in the present investigations and since all the micro structures of the materials were about the same before the tests it is also not expected that at least among the materials tested there was a significant influence of differences in the micro structure on oxidation behaviour.

As a conclusion from these investigations it may be recommendable for steels to be used in water vapour containing environments to keep the molybdenum content of the material as low as possible and rather replace molybdenum by tungsten as a carbide former in order to maintain the creep strength, since tungsten does not seem to have a negative effect on oxidation behaviour under these conditions and at the investigated temperature. Manganese may help slowing down the evaporation rate of volatile chromium containing hydroxyl species and in particular silicon seems to have a beneficial effect in water vapour containing environments with regard to slowing down the chromium depletion rates in the metal subsurface zone and, thus, extending the time to breakaway oxidation significantly. At lower water vapour contents (i.e. $4 \%$ ) it even seems to be able to prevent breakaway oxidation for long times (in the present case 10000 h). Furthermore Si may 
help with the repassivation effect after breakaway and with the restoration of the protective effect by facilitated scale crack healing.

\section{Acknowledgement}

The present work was financially supported by the Bundesministerium für Wirtschaft und Technologie via Arbeitsgemeinschaft industrieller Forschungsvereinigungen (AiF) under contract no. $11581 \mathrm{~N}$ and by the European Commission in the framework of the "Human Capital and Mobility" programme which is gratefully acknowledged. Thanks are also due to Mrs. Berghof-Hasselbächer for metallographic work.

\section{References}

1. Oehmingen, H. et al. VDI Report 1333, VDI-Verlag, Düsseldorf 1997.

2. Vossen, J.P.T.; Gawenda, P.; Rahts, K.; Röhrig, M.; Schorr, M.; Schütze, M. Materials at High Temperatures v. 14, 387, 1997.

3. Fuji, C.T.; Meussner, R.A.; J. Electrochem. Soc. v. 111, 1215, 1964.

4. Rahmel, A.; Tobolski, J. Corrosion Science v. 5, 333, 1965.

5. Armanet, F.; Vejux, A.; Beranger, G. In "Behaviour of High-Temperature Alloys in Aggressive Environments", Hrsg. I. Kirman et al., S. 423, The Metals Society, London 1980.

6. Ikeda, Y.; Nii, K.; Trans. JIM v. 26, 52, 1984.
7. Norby, T. Advances in Ceramics v. 23, 107, 1989.

8. Williams, C.R.; et al., Oxidation Characteristics of $9 \% \mathrm{Cr}$ Steels in Atmospheres Containing Water Vapour, Proc. EUROCORR '96, Paper III OR 10, Centre Français de l'Anticorrosion, Nice 1996.

9. Asteman, H.; Svensson, J. E.; Norell, M.; Johansson, L. G. Oxidation of Metals v. 54, 11, 2000.

10. Przybilla, W.; Schütze, M. The Role of Growth Stresses for the Structure of Oxide Scales on Nickel at 800 and $900^{\circ} \mathrm{C}$, Oxidation of Metals, v. 58, p. 103, 2002.

11. Echsler, H.; Przybilla, W.; Schütze, M.; Proc. EUROCORR 2000, IoM Communications LTD, London, 2000.

12. Schütze, M.; Renusch, D. M. Schorr, submitted to Materials at High Temperature

13. Computerprogram CHEMSAGE, Version 4.22, GTTTechnologies, Aachen 2000.

14. Dettenwanger, F.; Schorr, M.; Ellrich, J.; Weber, T.; Schütze, M. NACE-CORROSION 2001, paper 01151, NACE, Houston 2001.

15. Birks, N.; Pettit, F.S. Materials Science and Engineering A v. 143, 187, 1991.

16. Per Kofstad, High Temperature Corrosion, Elsevier Applied Science, 1988, ISBN 1-85166-154-9

17. Schütze, M. Protective Oxide Scales and Their Breakdown, Wiley, Chichester 1997.

18. Grünling, H.W.; Leistikow, S.; Rahmel A.; Schubert, F. in "Aufbau von Oxidschichten auf Hochtemperturwerkstoffen und ihre technische Bedeutung”, eds A. Rahmel, DGM, Oberursel, p. 7, 1983. 